\title{
PERILAKU PLATE GIRDER BADAN BERGELOMBANG
}

\author{
Arya Rizki Darmawan ${ }^{* 1}$, Agoes Soehardjono² dan \\ Wisnumurti $^{2}$ \\ 1 Mahasiswa / Program Magister / Teknik Sipil / Universitas Brawijaya Malang \\ 2 Dosen / Jurusan Teknik Sipil / Fakultas Teknik / Universitas Brawijaya Malang \\ Korespondensi : asusarya@gmail.com
}

\begin{abstract}
Plate girder is a composition from of several pieces of plate elements that have high slender ratio. Buckling on web is the main problem. Corrugated web is an innovation to resolve buckling problems. This research aims to get the effect of fold angle to shear capacity and get the collapse behavior that occurred. The research was conducted on a full scale in the laboratory and the ANSYS validation. This research concludes that the shear capacity of a flat-plate girder (conventional) will be increase by about $41 \%$ by making corrugated web geometric. In this research, the collapse occured in conventional girder plate is the collapse due to diagonal shear buckling in the area of 1/3 support, while for the collapse of the corrugated web girder is the collapse of torsion.
\end{abstract}

Keywords: plate girder, corrugated web, steel structure

\section{PENDAHULUAN}

Plate girder merupakan komponen struktur lentur yang tersusun dari beberapa elemen plat [1]. Karena plate girder dibuat secara terpisah, masing-masing dapat dirancang secara individual untuk menahan beban yang diterapkan dengan menggunakan proporsi yang memastikan bahwa berat sendirinya rendah dan mampu memikul beban yang tinggi. Plate girder bisa didesain dengan tinggi tanpa batas, sesuai dengan kebutuhan struktur. Namun dengan badan yang langsing dan tinggi yang cukup besar dapat membuat kemungkinan terjadinya tekuk pada badan. Sehingga banyak peneliti membuat inovasi baru untuk mengatasi tekuk pada badan langsing plate girder dengan menambah pengaku vertikal dan longitudinal serta membuat badan bergelombang (corrugated web).

Dalam penelitian ini memiliki beberapa tujuan yaitu mendapatkan pengaruh dari sudut lipatan, menganalisa kapasitas geser dari plate girder berbadan datar dan gelombang, serta mendapatkan perilaku keruntuhan yang terjadi.

\section{KAJIAN PUSTAKA}

2.1. Kapasitas Geser Corrugated Web Kekuatan geser dari plate girder corrugated web adalah berdasarkan dari tinggi dan ketebalan web, geometri dari corrugated dan material dari web tersebut. Corrugated atau yang bisa diartikan lipatan adalah untuk memberikan stabilitas pada badan dan sekaligus untuk menghilangkan penggunaan pengaku vertikal [2,3]. Dengan demikian, kapasitas geser tidak lagi bergantung pada jarak antar pengaku seperti yang sering dilakukan pada desain plate girder umumnya. Badan bergelombang tidak mentransfer tegangan longitudinal dari keseluruhan lentur girder, dan momen lentur diasumsikan ditahan oleh sayap.

$$
\begin{aligned}
& \left(\tau_{c r, L}\right) e l=k_{L} \frac{\pi^{2} E}{12\left(1-v^{2}\right)\left(w / t_{w}\right)^{2}} \\
& \left(\tau_{c r, G}\right) e l=k_{G} \frac{D_{x}{ }^{1 / 4} D_{y}{ }^{3 / 4}}{t_{w} h_{w}{ }^{2}}
\end{aligned}
$$

Dimana $D x$ dan $D y$ adalah kekakuan pelat orthotropic terhadap sumbu lemah dan sumbu kuat, dan $k_{G}$ merupakan faktor yang tergantung pada kondisi batas. Nilai $k_{G}$ adalah 31,6 untuk tumpuan sederhana di sepanjang tepi web dan 59,2 untuk tumpuan jepit di sepanjang tepi $w e b$, dan nilai $k_{L}$ adalah 5,34 untuk tumpuan sederhana dan 8,98 untuk tumpuan jepit disepanjang lipatan.

$$
D_{x}=\frac{q}{s} \frac{E t_{w}{ }^{3}}{12}
$$


$D_{y}=\frac{E I_{y}}{q}$

$I_{y}=2 b t_{w}\left(\frac{h_{r}}{2}\right)^{2}+\frac{t_{w} h_{r}{ }^{3}}{6 \sin \alpha}$

atau, tegangan geser elastis tekuk global dapat pula dirumuskan dalam persamaan 6 sebagai berikut:

$\left(\tau_{c r, G}\right) e l=k_{G} \frac{E t_{w}{ }^{1 / 2} b^{3 / 2}}{12 h_{w}{ }^{2}} F(\alpha, \beta)$

$F(\alpha, \beta)=\sqrt{\frac{(1+\beta) \sin ^{3} \alpha}{\beta+\cos \alpha}}\left\{\frac{3 \beta+1}{\beta^{2}(\beta+1)}\right\}^{3 / 4}$

$\alpha$ adalah sudut dari lipatan badan dan $\beta$ adalah rasio perbandingan antara lebar tekukan longitudinal (b) dengan panjang tekukan diagonal $(c)$.

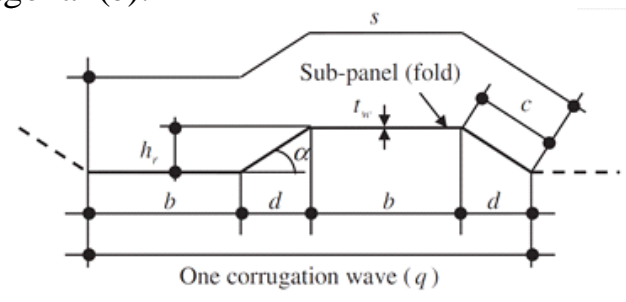

Gambar 1. Notasi geometri corrugated web

Ketika tegangan tekuk geser elastis telah melebihi $80 \%$ dari tegangan leleh geser ( $\tau y)$, persamaan tegangan tekuk inelastis dituliskan dalam persamaan berikut:

$\left(\tau_{c r}\right)$ inel $=\sqrt{0,8 \tau_{y}\left(\tau_{c r}\right) e l} \leq \tau_{y}$

\subsection{Kapasitas Desain Tekuk Geser menurut Driver [4]}

Persamaan 9 adalah rumusan untuk kapsitas geser nominal $\left(\tau_{n}, D\right)$ yang ditulis oleh Driver untuk digunakan gelagar jembatan dengan badan bergelombang. Persamaan ini dipengaruhi oleh efek tekuk lokal dan tekuk global yang dapat dilihat di persamaan 1 dan 2 .

$\tau_{n, D}=\sqrt{\frac{\left(\tau_{c r, L} \tau_{c r, G}\right)^{2}}{\left(\tau_{c r, L}\right)^{2}+\left(\tau_{c r, G}\right)^{2}}}$

\subsection{Kapasitas Desain Tekuk Geser menurut Sause \& Braxtan [5]}

Sause dan Braxtan juga mengusulkan rumusan untuk kapasitas tekuk geser gelagar jembatan dengan badan bergelombang yang ditulis dalam persamaan 10 .

$\tau_{n, S}=\tau_{y}\left(\frac{1}{\left(\lambda_{l, 3}\right)^{6}+2}\right)^{1 / 3}$ dimana $\lambda_{I, 3}$ adalah parameter kelangsingan yang ditentukan dalam persamaan 11 dengan nilai $\mathrm{n}$ $=3$. Parameter kelangsingan lokal $\left(\lambda_{L}\right)$ dan global $\left(\lambda_{G}\right)$ ditentukan dalam persamaan 12 dan 13. Nilai $k_{G}$ adalah 36 untuk tumpuan sederhana dan 68,4 untuk tumpuan jepit disepanjang tepi badan.

$$
\begin{aligned}
& \lambda_{I, n}=\lambda_{L} \lambda_{G}\left(\left(\frac{1}{\lambda_{L}}\right)^{2 n}+\left(\frac{1}{\lambda_{G}}\right)^{2 n}\right)^{1 / 2 n} \\
& \lambda_{L}=\sqrt{\frac{12\left(1-v^{2}\right) \tau_{y}}{k_{L} \pi^{2} E} \frac{w}{t_{w}}} \\
& \lambda_{G}=\sqrt{\frac{12 h_{w}{ }^{2} \tau_{y}}{k_{G} F(\alpha, \beta) E t_{w}{ }^{0,5} b^{1,5}}}
\end{aligned}
$$

\subsection{Kapasitas Desain Tekuk Geser menurut Moon [6]}

Untuk menghitung kapasitas tekuk geser $\left(\tau_{n, M}\right)$ menurut Moon, terlebih dahulu harus diketahui parameter tekuk geser $(\lambda s)$ dari badan bergelombang dengan persamaan 14. Koefisien tekuk geser $\left(k_{l}\right)$ kemudian akan dihitung dalam persamaan 15 .

$$
\begin{array}{ll}
\lambda_{s}=1,05 \sqrt{\frac{\tau_{y}}{k_{i} E}}\left(\frac{h_{w}}{t_{w}}\right) & \\
k_{l}=\frac{30,54}{5,34\left(h_{r} / t_{w}\right)^{-1,5}+5,72\left(w / h_{w}\right)^{2}} \\
\frac{\tau_{n, M}}{\tau_{y}}=1,0 & \text { untuk } \lambda_{s} \leq 0,6 \\
\frac{\tau_{n, M}}{\tau_{y}}=1-0,614\left(\lambda_{s}-0,6\right) & \text { untuk } 0,6<\lambda_{s} \leq \sqrt{2} \\
\frac{\tau_{n, M}}{\tau_{y}}=\frac{1}{\lambda_{s}{ }^{2}} & \text { untuk } \sqrt{2}<\lambda_{s}
\end{array}
$$

\section{METODOLOGI PENELITIAN}

\subsection{Tinjauan Umum}

Metode yang digunakan dalam penelitian ini adalah pengujian laboratorium serta validasi dengan numerik bantuan software ANSYS. Metode pengujian laboratorium dipilih untuk mencari pengaruh variabel tertentu terhadap variabel yang lain secara terkontrol dengan ketat dan dilakukan dengan sistematis dalam memperoleh data, sehingga data tersebut dapat digunakan dalam pembuatan keputusan dan kesimpulan. Sedangkan pengujian dengan numerik software bantu ANSYS dilakukan untuk memvalidasi hasil pengujian yang didapat di laboratorium, sehingga hasil dari pengujian laboratorium dapat dikomparasikan dengan hasil numerik bantuan ANSYS. 
Tabel 1. Konsep, variabel dan indikator penelitian

\begin{tabular}{|c|c|}
\hline Konsep & Variabel bebas \\
\hline $\begin{array}{l}\text { Peningkatan kapasitas tegangan } \\
\text { geser kritis dari struktur plat } \\
\text { girder dengan pemberian } \\
\text { geometri badan bergelombang } \\
\text { yang mampu meningkatkan } \\
\text { kekakuan dan kuat tekuk }\end{array}$ & $\begin{array}{c}\text { Variabel bebas dalam penelitian } \\
\text { ini adalah sudut gelombang }(\alpha) \\
\text { pada badan plat girder }\end{array}$ \\
\hline Variabel terikat & Indikator \\
\hline $\begin{array}{c}\text { Variabel terikat dalam } \\
\text { penelitian ini adalah besaran } \\
\text { kapasitas tegangan geser kritis } \\
\text { ( } \tau \text { cr) yang diolah dari data hasil } \\
\text { pembacaan nilai regangan } \\
\text { geser }\end{array}$ & $\begin{array}{c}\text { Bekerjanya sistem pemberian } \\
\text { geometri badan bergelombang } \\
\text { pada plat girder ditunjukkan } \\
\text { dengan adanya peningkatan } \\
\text { parameter-parameter dari } \\
\text { variabel terikat }\end{array}$ \\
\hline
\end{tabular}

\subsection{Data Material Penelitian}

Material yang digunakan adalah lembaran baja yang berada di pasaran Kota Malang. Untuk mendapatkan data material tersebut, dibuat benda uji kuat tarik baja menurut SNI 07-0371-1998 [7]. Pada SNI 07-0371-1998 mengenai batang uji tarik berbahan logam terdapat 14 model variasi benda uji sesuai dengan bentuk dan tebalnya. Dan model benda uji yang akan dibuat untuk penelitian ini adalah nomor 14B. Pengujian kuat tarik baja ini bertujuan untuk memperoleh data material berupa tegangan leleh (fy), tegangan ultimat $(f u)$, dan nilai modulus elastisitas material $(E)$. Yang nantinya data tersebut akan digunakan dalam langkah perhitungan kapasitas benda uji plate girder badan bergelombang, serta untuk proses input data material pengujian secara numerik dengan bantuan ANSYS.

\subsection{Model Geometri Benda Uji}

Tabel 2. Ukuran penampang benda uji

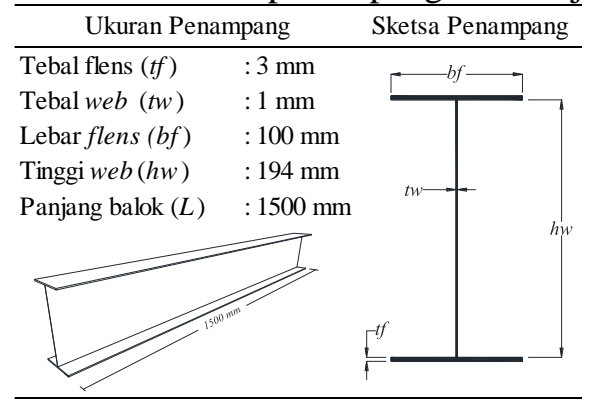

Dari ukuran yang telah ditentukan pada Tabel 2, maka dapat dilakukan permodelan benda uji dengan membuat benda uji plate girder berpengaku (konvensional) dan plate girder dengan badan bergelombang. Model dan beberapa variasi yang akan dibuat disajikan dalam Tabel 3. Yang akan dilakukan pengujian laboratorium hanya model A0, A1 dan A5, sedangkan yang dilakukan pengujian secara numerik adalah semua model dari A0 sampai A5.

Tabel 3. Daftar model pengujian

\begin{tabular}{ccccccccc}
\hline Model & $\mathrm{a}(\mathrm{mm})$ & $\mathrm{tw}(\mathrm{mm})$ & $\mathrm{hw}(\mathrm{mm})$ & $\mathrm{bf}(\mathrm{mm})$ & $\mathrm{tf}(\mathrm{mm})$ & $\mathrm{b}(\mathrm{mm})$ & $\mathrm{d}(\mathrm{mm})$ & $a^{0}$ \\
\hline A0 & 500 & 1 & 194 & 100 & 3 & - & - & - \\
$\mathrm{A} 1$ & - & 1 & 194 & 100 & 3 & 80 & 45 & 15 \\
$\mathrm{~A} 2$ & - & 1 & 194 & 100 & 3 & 80 & 45 & 20 \\
A3 & - & 1 & 194 & 100 & 3 & 80 & 45 & 25 \\
A4 & - & 1 & 194 & 100 & 3 & 80 & 45 & 30 \\
A5 & - & 1 & 194 & 100 & 3 & 80 & 45 & 35 \\
\hline
\end{tabular}

\subsection{Metode Pelaksanaan Pengujian Model}

1. Tahapan persiapan

Pada tahap persiapan ini dilakukan pemeriksaan kondisi lembaran baja yang didapatkan dari pasar Kota Malang. Pemeriksaan ini meliputi pengukuran tebal lembaran, kondisi lembaran dan mutu lembaran baja.

2. Tahapan pembuatan benda uji

Agar dapat meminimalisir kesalahan dalam pengujian, masing-masing model $\mathrm{A} 0, \mathrm{~A} 1$ dan A5 dibuat sebanyak 2 buah benda uji. Pembuatan benda uji seluruhnya dilakukan di VEDC Kota Malang.

3. Tahapan pengujian

Model benda uji akan diperletakan sendi dan rol. Pengujian yang dilakukan adalah two point load test. Dengan beban dua titik pada balok bertujuan untuk mempermudah pelaksanaan pengujian dan agar beban yang diaplikasikan dapat sentris. Beban akan diaplikasikan di setiap $1 / 3$ bentang dan pembebanan balok dilakukan dengan alat Jack Hydrolic. Beban akan diberikan secara bertahap setiap $50 \mathrm{~kg}$ hingga balok mengalami keruntuhan. Untuk mengukur besaran lendutan yang terjadi maka dipasang 3 buah Linear Variabel Differential Transformer (LVDT) pada arah bawah dan arah samping seperti yang ditunjukkan pada Gambar 3.

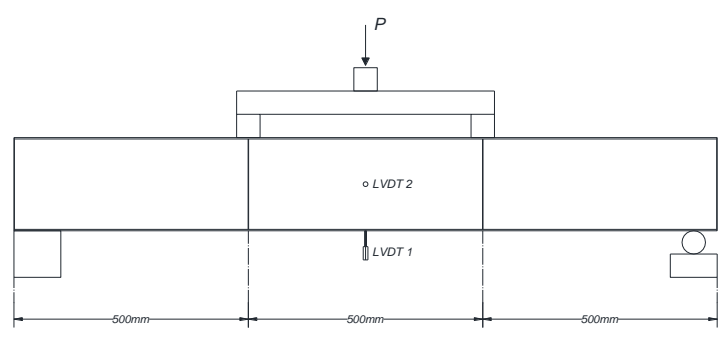

Gambar 3. Ilustrasi pengujian balok 
Untuk melakukan pengukuran regangan digunakan electrical strain gage pada model benda uji. Ada 3 arah regangan yang akan diukur, sehingga dirangkai 3 buah strain gage sesuai rectangular rosette [8].

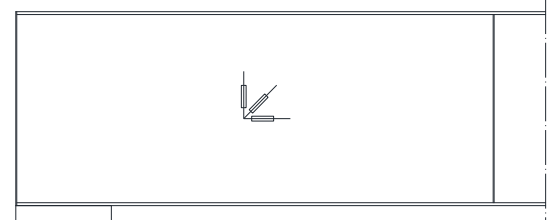

Gambar 4. Perletakan strain gage

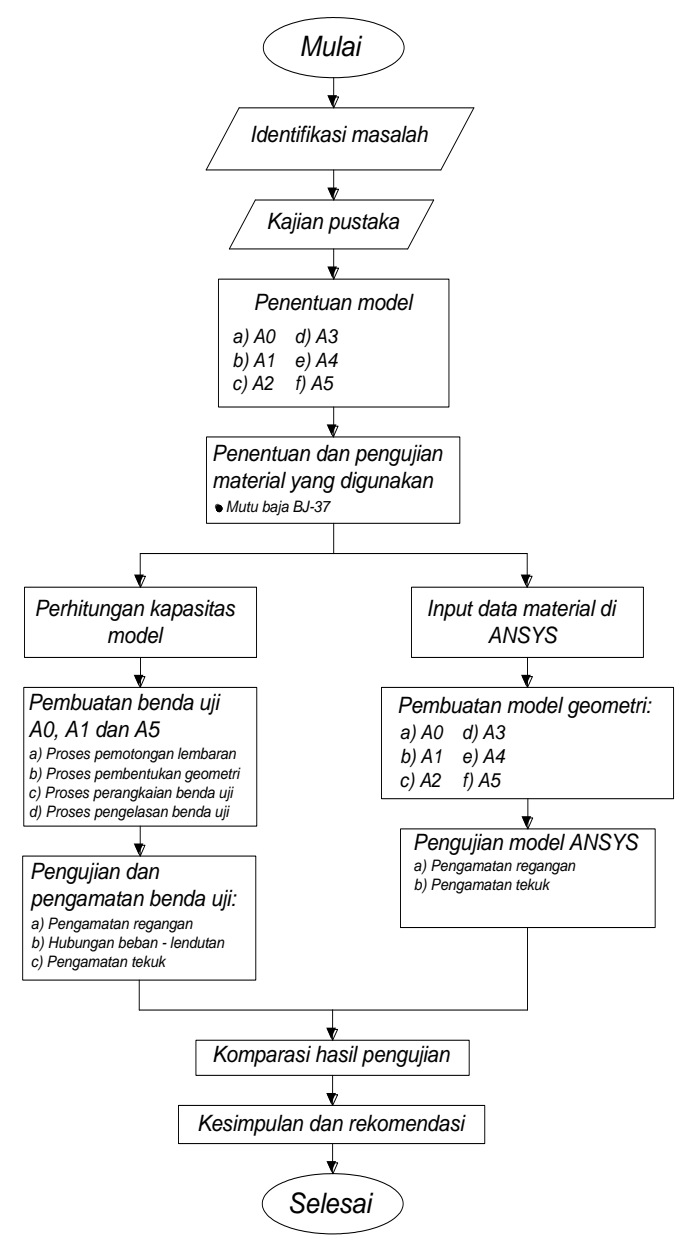

Gambar 5. Diagram alir penelitian

\section{HASIL PEMBAHASAN}

\subsection{Hasil Uji Tarik Plat Baja}

Pengujian tarik plat baja dilakukan di Laboratorium Struktur Fakultas Teknik Jurusan Teknik Sipil Universitas Negeri Malang. Dalam pengujian tarik ini digunakan alat
Universal Test Machine, namun pembacaan pertambahan panjang akibat penarikan digunakan tambahan alat berupa Extensometer yang terhubung langsung dengan komputer. Extensometer akan direkatkan dengan karet diantara Lo benda uji.

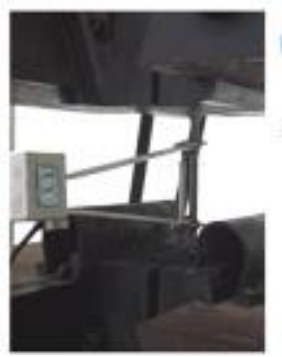

(a)

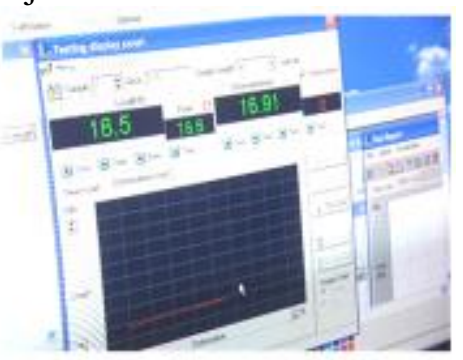

(b)
Gambar 6. Pengujian tarik plat baja (a) pemasangan Extensometer, hasil bacaan Extensometer yang tersambung dengan komputer

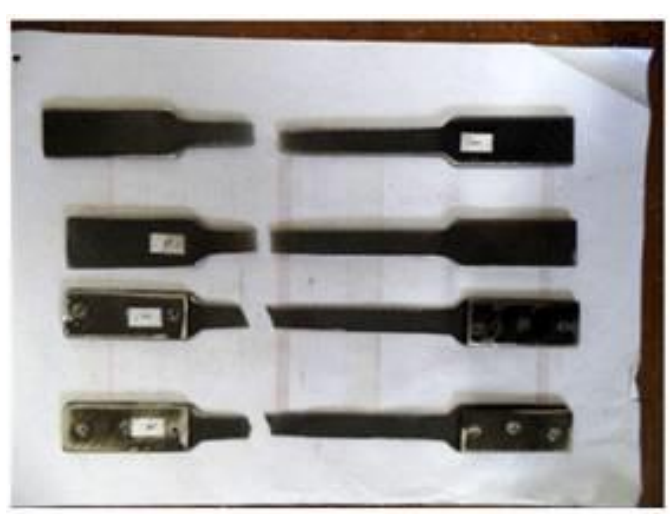

Gambar 7. Bentuk putus plat baja akibat pengujian tarik

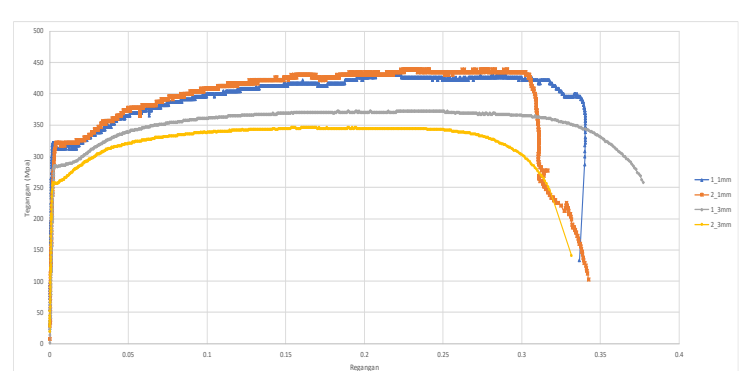

Gambar 8. Kurva hubungan antara tegangan dengan regangan hasil dari pengujian tarik plat baja

Tabel 4. Rekapitulasi hasil uji tarik plat baja

\begin{tabular}{cccc}
\hline Nama Benda Uji & fy $(\mathrm{MPa})$ & fu $(\mathrm{MPa})$ & $\mathrm{E}(\mathrm{MPa})$ \\
\hline No 1 Tebal 1mm & 312.08 & 429.76 & 259833 \\
No 2 Tebal 1mm & 316.40 & 434.16 & 230287 \\
No 1 Tebal 3mm & 272.58 & 371.80 & 132198 \\
No 2 Tebal 3mm & 246.42 & 343.78 & 202736 \\
\hline
\end{tabular}




\subsection{Hasil Pengujian}

\subsubsection{Pembahasan model plate girder berbadan datar (Model A0)}

Dalam analisa matematis [9], dapat disimpulkan bahwa plate girder akan mengalami kegagalan geser pada saat beban mencapai sekitar $3000 \mathrm{~kg}$ dan tegangan geser kritis pada plat badan sekitar 33 Mpa (elastis) dan $70 \mathrm{Mpa}$ (inelastis). Plate girder akan direncanakan mengalami kerusakan tekuk diagonal di daerah badan 1/3 bentang. Arah tekan yang menyebabkan plate girder mengalami tekuk geser diilustrasikan dalam Gambar 9. Dalam pengujian laboratorium dilakukan setting up seperti Gambar 10. Pada pengujian ini akan diukur lendutan kebawah dan kesamping, serta nilai regangan yang didapat dari susunan strain gage rectangular rosette. Plate girder akan diberikan beban secara bertahap hingga mengalami keruntuhan.

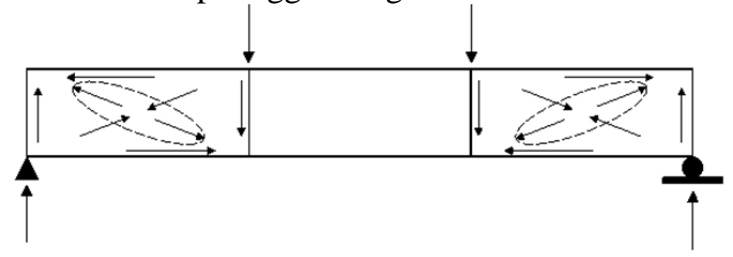

Gambar 9. Ilustrasi arah tekan pada bidang badan plate girder yang akan menyebabkan tekuk diagonal (tekuk akibat geser)

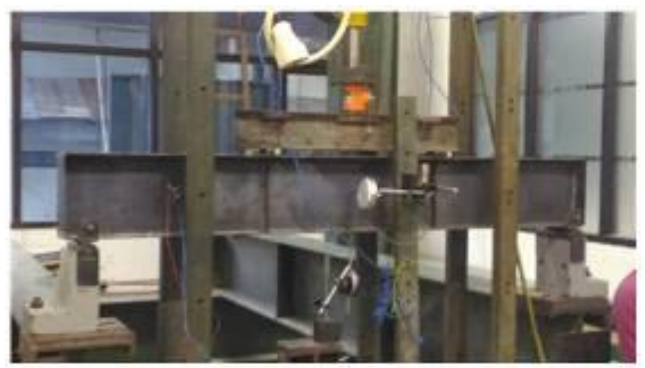

Gambar 10. Setting up pengujian plate girder

Pada saat pengujian, plate girder mengalami tekuk badan pada daerah 1/3 bentang dan tumpuan. Awal mula tekuk terjadi sekitar beban $2000 \mathrm{~kg}$, dan struktur mengalami keruntuhan (kapasitas puncak) sekitar $3400 \mathrm{~kg}$. Tegangan geser terjadi sebesar $79.78 \mathrm{Mpa}$ saat regangan geser mencapai leleh sekitar 0.00127 . Angka tegangan geser yang terjadi sebesar $79.78 \mathrm{Mpa}$ ini mendekati dengan nilai tegangan geser kritis plate girder secara matematis yang sebesar $70 \mathrm{Mpa}$ (inelastis), serta beban puncak sebesar $3400 \mathrm{~kg}$ mendekati dengan angka beban maksimum secara analisa matematis yang sebesar $3000 \mathrm{~kg}$. Hal ini menunjukkan bahwa hasil pengujian untuk model A0 (plate girder berbadan datar) menyerupai hasil analisa matematis sesuai perhitungan SNI.
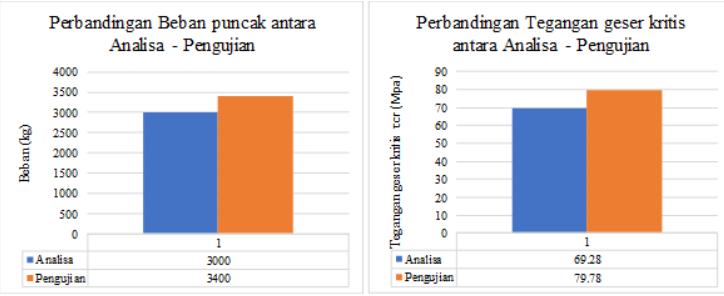

Gambar 11. Perbandingan hasil analisa matematis dengan pengujian untuk benda uji Model A0 (plate girder berbadan datar)

Keruntuhan yang terjadi dari kedua buah benda uji A0 (A0-1 dan A0-2) menunjukkan tekuk geser diagonal sesuai teori arah tekan yang dihasilkan oleh gaya geser. Pada plate girder berbadan datar ini mengalami tekan diagonal disepanjang 1/3 tumpuan. Dan pada daerah lapangan (tengah) tidak mengalami tekuk, sehingga keruntuhan yang terjadi adalah keruntuhan geser sesuai yang digambarkan pada teori ilustrasi Gambar 9. Panjang tekuk diagonal dibatasi oleh pengaku vertikal yang dipasang setiap jarak 500mm.

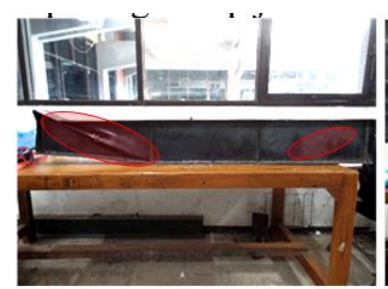

(a)

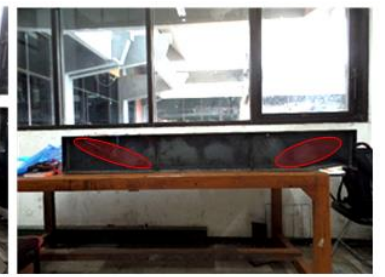

(b)
Gambar 12. Bentuk keruntuhan struktur (a) keruntuhan model A0-1, keruntuhan model A0-2

\subsubsection{Pembahasan model plate girder badan bergelombang $\alpha=15^{\circ}$ dan $\alpha=35^{\circ}$}

Untuk mengetahui kapasitas geser dari plate girder badan bergelombang secara matematis, digunakan rumusan dari beberapa teori yaitu Driver, Sause dan Moon. Dari rumusan ketiga teori tersebut didapat nilai tegangan geser kritis untuk plate girder badan bergelombang dengan masing-masing sudut lipatan. 
Tabel 5. Rekapitulasi perhitungan kapasitas tegangan geser kritis ( $\tau \mathrm{cr})$ masing-masing model dengan metode driver, sause dan moon

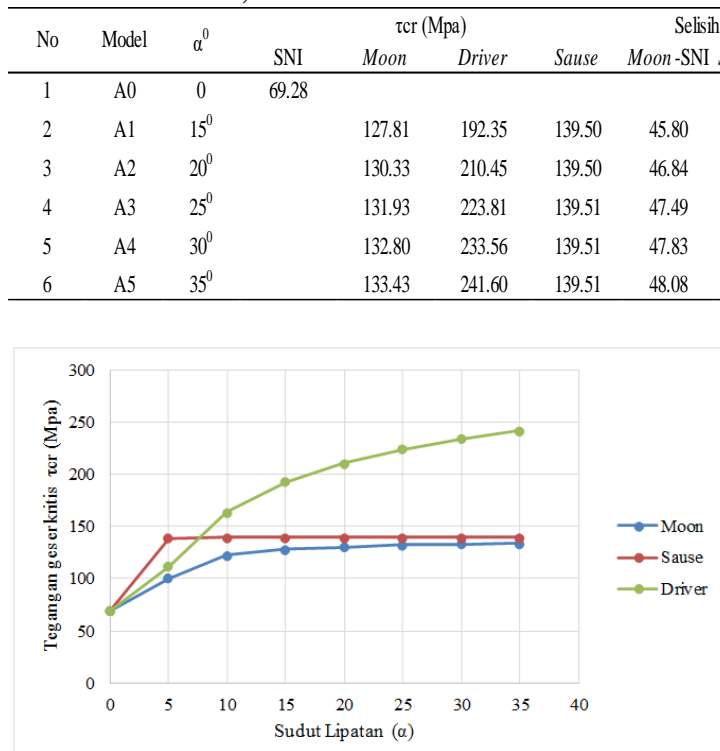

Gambar 13. Kurva hubungan sudut lipatan $(\alpha)$ dengan tegangan geser kritis $(\tau \mathrm{cr})$ sesuai metode analisa teori

Dari Tabel 5, bisa dibuat kurva hubungan antara sudut lipatan dengan tegangan geser kritis $(\tau c r)$ yang disajikan dalam Gambar 13, sehingga bisa dilihat peranan sudut lipatan terhadap kapasitas geser dari sebuah struktur plate girder. Terlihat peningkatan kapasitas geser yang cukup besar dari plate girder berbadan datar dengan plate girder badan bergelombang, namun pada saat sudut lipatan $15^{0}$ sampai sudut lipatan $35^{\circ}$ garis kurva cenderung hampir datar. Hal ini menunjukkan plate girder dengan sudut lipatan $15^{\circ}$ dengan sudut $35^{\circ}$ tidak menciptakan kapasitas geser yang cukup berbeda.

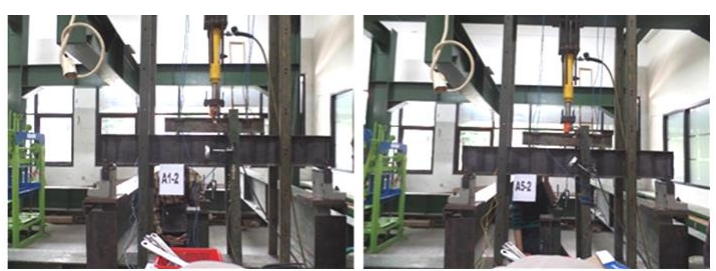

Gambar 14. Setting up pengujian plate girder badan bergelombang (a) Model A1 $\left(\alpha=15^{0}\right), \quad$ (b) Model A5 $\left(\alpha=35^{\circ}\right)$

Keruntuhan yang terjadi pada plate girder badan bergelombang ini yaitu terjadinya keruntuhan torsi. Terjadinya keruntuhan torsi ini diakibatkan tidak adanya pengaruh pengaku lateral pada saat pengujian, sehingga balok bekerja secara tunggal. Model A1 $\left(\alpha=15^{0}\right)$ mencapai beban maksimum sebesar $3080 \mathrm{~kg}$ dan mencapai nilai tegangan geser terjadi sebesar 50.26 Mpa saat saat beban sebesar $50.342090 \mathrm{~kg}$. Sedangkan Model A5 $\left(\alpha=35^{\circ}\right)$ hanya 50.34 mencapai beban maksimum sebesar $2990 \mathrm{~kg}$ 50.34 dan tegangan geser terjadi sebesar $48.75 \mathrm{Mpa}$ 50.34 saat beban mencapai $2090 \mathrm{~kg}$.

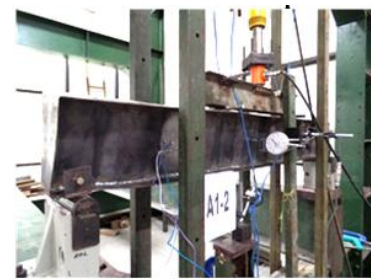

(a)

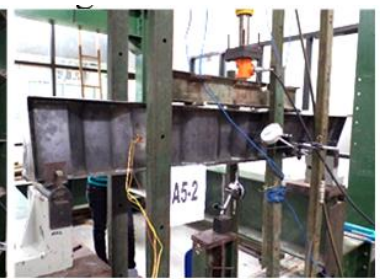

(b)
Gambar 15. Keruntuhan torsi plate girder badan bergelombang (a) Model A1 $\left(a=15^{\circ}\right), \quad(b)$ Model A5 $\left(\alpha=35^{0}\right)$

Dari keruntuhan struktur yang terjadi terlihat badan plate girder tidak terjadi tekuk. Hal ini menyebabkan hasil bacaan regangan dari strain gage rectangular rosette hanya sebatas regangan elastis. Sehingga perhitungan nilai tegangan geser pun berdasarkan rumusan rosette hanya didapat nilai tegangan geser di kondisi elastis saja. Namun dapat dilihat peran dari sudut lipatan badan bergelombang menghasilkan nilai tegangan geser yang terjadi lebih kecil. Rekap perbandingan nilai tegangan geser yang terjadi saat kondisi beban tertentu disajikan dalam Tabel 6.

Tabel 6. Rekap perbandingan nilai tegangan geser masing-masing model dalam kondisi beban tertentu

\begin{tabular}{ccccc}
\hline Kondisi beban mencapai sekitar 1.3 Ton & & & \\
\hline Model & Beban $(\mathrm{kg})$ & Nilai tegangan geser yang terjadi (Mpa) & Regangan geser & Selisih $(\%)$ \\
\hline A0-2 (datar) & 1370 & 41.05 & 0.000550357 & \\
A1-2 $\left(\alpha=15^{0}\right)$ & 1330 & 24.77 & 0.000279653 & 39.66 \\
A5-2 $\left(\alpha=35^{0}\right)$ & 1340 & 19.21 & 0.000216912 & 53.20 \\
\hline Kondisi beban mencapai sekitar 2 Ton & & & \\
\hline \multicolumn{7}{c}{ Model } & Beban $(\mathrm{kg})$ & Nilai tegangan geser yang terjadi (Mpa) & Regangan geser & Selisih (\%) \\
\hline A0-2 (datar) & 2000 & 73.52 & 0.001273392 & \\
A1-2 $\left(\alpha=15^{0}\right)$ & 2070 & 37.80 & 0.000426792 & 48.58 \\
A5-2 $\left(\alpha=35^{0}\right)$ & 2020 & 29.89 & 0.000337497 & 59.34 \\
\hline Kondisi beban mencapai sekitar 3 Ton & & & \\
\hline Model & Beban $(\mathrm{kg})$ & Nilai tegangan geser yang terjadi (Mpa) & Regangan geser & Selisin (\%) \\
\hline A0-2 (datar) & 2940 & 78.36 & 0.001303889 & \\
A1-2 $\left(\alpha=15^{\circ}\right)$ & 2940 & 50.26 & 0.000567486 & 35.85 \\
A5-2 $\left(\alpha=35^{0}\right)$ & 2940 & 48.75 & 0.000550415 & 37.78 \\
\hline
\end{tabular}




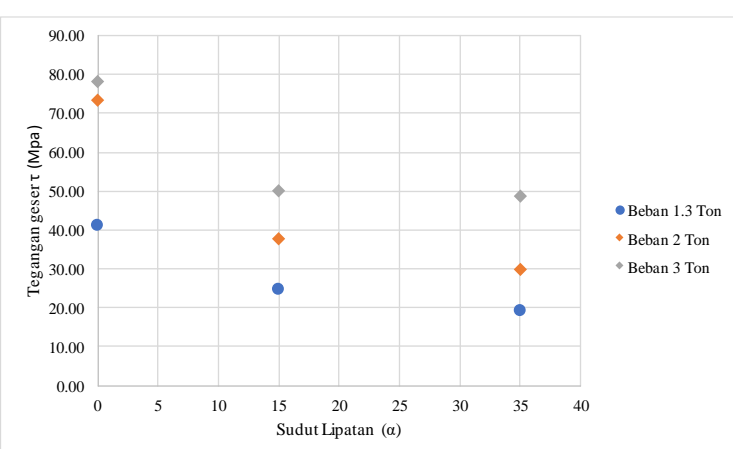

Gambar 16. Hubungan sudut lipatan dengan tegangan geser yang terjadi berdasarkan hasil pengujian laboratorium

Dengan adanya pembuatan geometri badan bergelombang, kuat tekuk geser akan meningkat. Peningkatan kuat tekuk geser ini dapat dilihat dengan adanya pengurangan tegangan geser yang terjadi dalam kondisi-kondisi beban tertentu yang diberikan terhadap struktur plate girder. Berdasarkan hasil pengamatan laboratorium, pembuatan geometri badan bergelombang dapat mengurangi tegangan geser yang terjadi sekitar $41 \%$ dari tegangan geser yang terjadi dari plate girder berbadan datar. Angka selisih 41\% dari hasil pengamatan pengujian laboratorium (terbatas hanya kondisi elastis), mendekati dengan angka penambahan kapasitas tegangan geser kritis $(\tau \mathrm{cr})$ dari perhitungan matematis berdasarkan metode Sause dan Moon.

Berdasarkan rekapitulasi perhitungan tegangan geser kritis yang disajikan dalam Tabel 5 menyimpulkan hal yang hampir sama dengan hasil pengujian laboratorium. Yaitu adanya pertambahan kapasitas tegangan geser sekitar 45\% (metode Moon) dengan dibuatnya geometri badan bergelombang.

\subsubsection{Validasi dengan Bantuan Program Numerik ANSYS Workbench}

Untuk dapat memvalidasi hasil pengujian dan analisa teoritis dalam penelitian ini digunakan program bantu komputer ANSYS Workbench versi 14.5. Tahap awal dalam program ini yaitu memasukkan data material berupa Non Linier Steel (Structural Steel NL) yang didapat dari hasil uji tarik material plat baja. Pembuatan geometri model dilakukan dengan import dari model yang telah dibuat dengan Autocad. Kondisi perletakan serta kondisi beban dibuat sama dengan kondisi saat pengujian laboratorium.

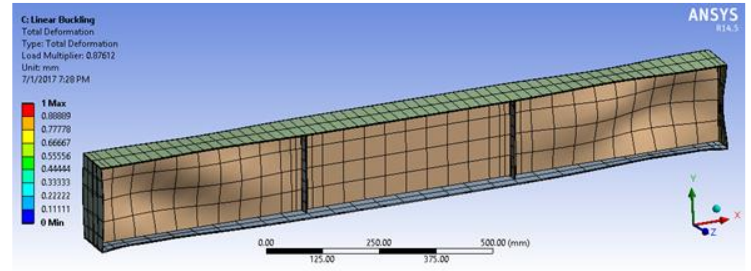

(a)

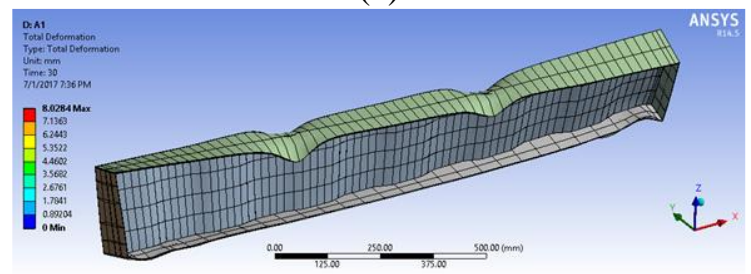

(b)

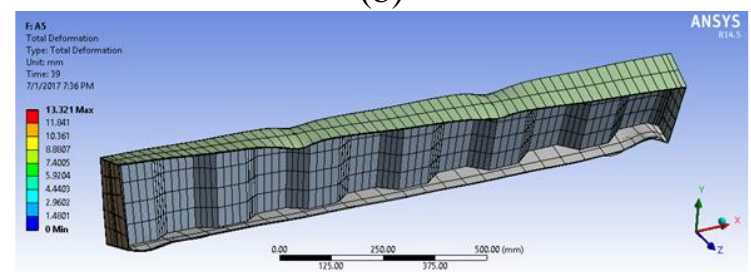

(c)

Gambar 17. Keruntuhan berdasarkan analisa ANSYS (a) A0, (b) A1 dan (c) A5

Gambar 17 menunjukkan pola keruntuhan plate girder berbadan datar hingga badan bergelombang. Pola keruntuhan yang terjadi menyerupai dengan pola keruntuhan pada pengujian laboratorium. Dimana pada plate girder berbadan datar mengalami tekuk geser diagonal di sepanjang $1 / 3$ bentang daerah tumpuan. Serta untuk pola keruntuhan plate girder badan bergelombang mengalami keruntuhan torsi. Tekuk lokal yang disebabkan gaya tumpu juga terjadi pada daerah tumpuan dan daerah beban. Hal ini dikarenakan perletakan tumpuan lebih maju $5 \mathrm{~cm}$ dari tepi bentang, serta tidak diberinya pengaku vertikal tambahan di daerah tumpuan dan di daerah pemberian beban. Pengaku tambahan tersebut seharusnya diberikan agar mencegah tekuk lokal yang tidak diinginkan. Dari hasil analisa dengan bantuan program ANSYS didapat besaran tegangan geser yang terjadi pada badan plate girder. Pengambilan nilai tegangan geser yang terjadi ini diambil dalam kondisi-kondisi beban sesuai dengan pengujian secara laboratorium, yaitu saat beban 1.3 ton, 2 ton, dan 3 ton. Perbandingan besaran tegangan geser yang terjadi antara pengujian secara laboratorium dengan ANSYS disajikan dalam Gambar 18. 


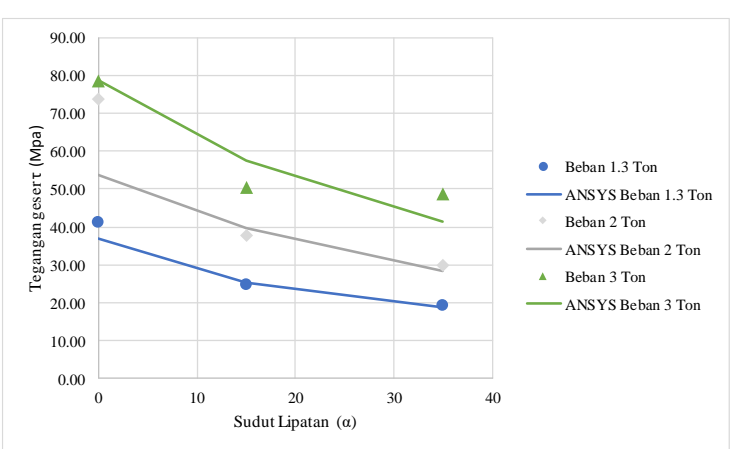

Gambar 18. Perbandingan besaran tegangan geser kritis antar sudut lipatan secara pengujian laboratorium dan secara pengujian ANSYS

Dari Gambar 18 dapat disimpulkan bahwa hasil pengujian secara laboratorium dan ANSYS menunjukkan penurunan besaran tegangan geser yang terjadi pada antar sudut lipatan dalam kondisi beban yang sama. Hal ini bearti semakin besar sudut liapatan badan plate girder, maka kapasitas geser juga akan semakin meningkat. Namun ada perilaku berbeda antara pengujian secara laboratorium dengan ANSYS. Dimana saat sudut lipatan sebesar $15^{0}$ sampai $35^{\circ}$, pengujian ANSYS menunjukkan terjadinya penurunan terus menerus secara linier. Hal ini dikarenakan pengujian ANSYS hanya sampai pada tahap static structural dan linier buckling saja. Dan juga setting perilaku pengujian secara ANSYS tidak dapat sama persis dengan pengujian di laboratorium.

\section{KESIMPULAN DAN SARAN 6.1. Kesimpulan}

Dari hasil penelitian yang telah dibahas dapat ditarik beberapa kesimpulan sebagai berikut:

1. Sudut lipatan badan bergelombang mempengaruhi kapasitas geser dari plate girder. Dimana semakin besar sudut lipatan gelombang, maka kapasitas geser dari suatu balok juga akan ikut bertambah.

2. Dengan ditunjukkan perbandingan kapasitas geser dari plate girder berbadan datar dengan plate girder badan bergelombang, ada terlihat peningkatan kapasitas geser sekitar $41 \%$ dengan dibuatnya geometri badan bergelombang. Namun setelah dilakukan variasi sudut mulai dari $15^{0}$ sampai $35^{\circ}$, perubahan kapasitas geser tidak terlalu besar (cenderung seragam).

3. Pola keruntuhan yang dialami oleh plate girder badan bergelombang adalah keruntuhan torsi.

\subsection{Saran}

Berdasarkan kesimpulan dari penelitian yang telah dilakukan terdapat beberapa saran untuk menyempurnakan penelitian selanjutnya yaitu sebagai berikut:

1. Jika dilihat kapasitas geser dari perubahan sudut lipatan gelombang antara $15^{\circ}$ hingga $35^{0}$ cenderung seragam, maka untuk penelitian selanjutnya dapat melakukan percobaan dengan memvariasikan jumlah lipatan gelombang. Agar dapat diketahui pengaruh dari jumlah lipatan gelombang dengan sudut lipatan yang sama atau berbeda.

2. Agar penelitian selanjutnya dapat berkembang, dapat dilakukan pengujian dengan adanya pengaruh pengaku lateral.

\section{DAFTAR PUSTAKA}

[1] Salmon, C. G., dkk. Struktur Baja Desain dan Perilaku 2. Jakarta: PT. Gramedia Pustaka Utama. 1996.

[2] Hassanein, M. F., dkk. Behavior of bridge girders with corrugated webs: (I) Real boundary condition at the juncture of the web and flanges. Elsevier Science Direct. Engineering Structures 57. 2013: 554-564.

[3] Hassanein, M. F., dkk. Behavior of Bridge Girders with Corrugated Webs: (II) Shear Strength and Design. Elsevier Science Direct. Engineering Structures 57. 2013: 544-553.

[4] Driver, R. G., dkk. Shear Behavior of Corrugated Web Bridge Girders. Journal of Structural Engineering ASCE 0733-9445. 2006: 132:2 (195).

[5] Sause, R., dkk. Corrugated Web Girder Shape and Strength Criteria. Bethlehem: Penndot Research Lehigh University. 2003.

[6] Jiho, Moon, dkk. Shear Strength and Design of Trapezoidally Corrugated Steel Webs. Elsevier Science Direct. Journal of Constructional Steel Research 65. 2009: 1198-1205.

[7] Anonim. SNI 07-0371-1998. Badan Standar Nasional. 1998.

[8] Suhendro, B. Teori Model Struktur dan Teknik Eksperimen. Yogyakarta: Beta Offset. 2000.

[9] Anonim. SNI 03-1729-2002. Departemen Pekerjaan Umum. 2002. 